\title{
HETEROGENEIDAD DE LAS MÁSCARAS: ENTRE EL CARNAVAL DE BAJTÍN Y EL GROTESCO CRIOLLO DE DISCÉPOLO
}

\author{
Heterogeneity of the masks: between Bakhtin's carnival and \\ Discépolo's grotesco criollo
}

$9-23$

Amado Láscar*

\section{Resumen}

El artículo intenta establecer un paralelo entre el concepto de la máscara carnavalesca concebida por Mijaíl Bajtín en Rabelais y su mundo, y también en otros escritos, y la máscara del teatro Grotesco criollo en Buenos Aires, en las primeras décadas del siglo XX. El artículo comienza por definir semejanzas y diferencias en el uso de estas dos máscaras. En el caso medieval, la máscara es utilizada como herramienta de ecualización y de catarsis social y en el caso del grotesco criollo, la máscara es articulada como una herramienta de conformación y adaptación social. Es así como las funciones prácticas y estéticas de ambas máscaras, aunque son complementarias en términos de sus ingredientes (máscara-función social-orden social), son opuestas en cuanto a su implementación y valencia comunitaria. La máscara del carnaval es una máscara que intenta romper de forma momentánea el orden establecido para poder mantenerlo en el largo plazo. En cambio, la máscara grotesca es una máscara que opera desde adentro del individuo y la familia, obligándolo a estabilizar costumbres, valores o expectativas nacionales, en la comunidad inmigrante - extranjera y campesina (gaucha) avecindada en la periferia de Buenos Aires-, con el objeto de autoasegurar su subsistencia física, a contramano de la sanidad emocional y social creada por esta acción en estos sujetos marginales desplazados.

Palabras clave: Grotesco criollo, Inmigración, Bajtín, Carnavalesco.

\section{Abstract}

This article attempts to establish a parallel between Mikhail Bakhtin's concept of carnival's mask in Rabelais and His World and other writings, and the mask in Grotesco Criollo Theater in Buenos Aires, during the first decades of the twentieth century. The article begins by defining similarities and differences in the use of these two masks. In the medieval case, the mask is used as a tool of equalization and social catharsis, and in the Grotesco Criollo, the mask is articulated as a shaping tool for conformity and social adaptation. Thus, the practical and aesthetic functions of both masks, though complementary in terms of their ingredients (mask/ social function/social order), are opposites in their implementation and community values. The carnival mask is a mask trying to break the established order momentarily, simply to keep it in the end. Instead, the grotesque mask is a mask that operates from within the individual and the family forcing him/ her to stabilize national customs, values, expectations for the suburban immigrant community (foreign and peasant) displaced to Buenos Aires' periphery to self-ensure their physical survival. However, such insurance often comes at the cost of emotional and social wellbeing of these displaced marginal subjects.

Key words: Immigration, Argentinian Immigration Theater, Carnavalesque. 


\section{INTRODUCCIÓN}

La presencia de la máscara como artefacto y como concepto ha cumplido en la historia occidental variados propósitos, tenido diversos significados y generado distintos efectos dependiendo de la situación y el contexto donde se haya suscitado. Aunque el objetivo literal de llevar una máscara es el ocultamiento del rostro para conseguir algún efecto social (cómico, dramático, diabólico, religioso, punitivo, etcétera) y que puede tener variados orígenes y razones. Para nuestro tema, el motivo y el resultado de llevarla establecen una relación de al menos tres elementos: el rostro, la máscara y el observador/interlocutor.

En latín, y en las lenguas romances, además que en lengua inglesa, alemana y holandesa, persona significa máscara, es decir, que en el inconsciente colectivo de estas lenguas europeas hay un reconocimiento tácito que nuestra apariencia pública es una representación y no una sencilla presentación de quienes somos, con un notorio impacto en la identidad y consecuentemente en la autoestima del sujeto a nivel privado, como también confusión entre lo real y lo imaginario a nivel colectivo. En resumen, la máscara establece socialmente una separación entre quienes somos y el papel que estamos representando en el mundo (o el rol con que nos estemos identificando en la sociedad) con todas las consecuencias que una acción así es capaz de provocar tanto a nivel individual como colectivo.

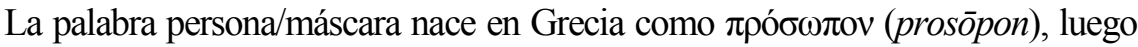
en Etruria pasa a llamarse phersu y finalmente en Roma deviene en personae. Es un hecho significativo que la tradición grecolatina, como uno de los vectores definitorios de la civilización occidental, haya percibido y reconocido semióticamente que para existir como ciudadano sería menester representar un personaje. En términos individuales y colectivos, lo problemático del asunto es que en el intento el enmascarado puede terminar identificándose con la persona representada, olvidándose de su propia voz (el ojo como ventana -no como opinión- que observa desde la infancia: nuestra básica consciencia). En suma, Occidente, a partir de uno de sus modelos culturales fundacionales más influyentes, ha establecido una disociación/dislocación entre el ser natural y el existir civilizado, creando desde su fundación una dicotomía casi irreconciliable entre el uno y lo otro ${ }^{1}$. Freud analiza con detención este asunto desde un punto de vista psicoanalítico en uno de sus textos seminales: Civilización y sus descontentos (1930); también el estructuralismo clásico, con el concepto de actante a partir de Greimas, On Meaning (1987), que en los años

\footnotetext{
${ }^{1}$ Esta idea no pretende anteponer ser a existir, o proponer una visión idealista de la realidad, sino que establecer que aunque el existir nos determina como sujetos sociales no somos meros productos de las interacciones sociales porque nuestra base existencial es un sujeto cognoscente, si fuera así el proceso de socialización no causaría tantos traumas y sufrimientos para justificar la existencia y el tratamiento emocional que es el tema de los psicólogos.
} 
sesenta es observado desde el punto de vista del significado o incluso acción de las partes constituyentes como determinado por la interacción de la totalidad; más tarde Jack Derrida preferirá utilizar su propia filosofía para decirlo: "nada existe fuera del contexto", Margins of Philosophy (1982), en el sentido que sin el sistema codificador (Langue para Sassure) no puede articularse ningún significado singular (Parole para Sassure).

En segundo lugar es necesario considerar el aspecto grotesco de la ecuación debido a que es un tema presente tanto en el carnaval analizado por Mijaíl Bajtín (en su versión callejera como novelística) como en el teatro bonaerense de principios del siglo XX. La palabra grotesco procede de la palabra latina grotto, que significa cueva o "gruta" y que proviene de la palabra griega krypte que significa lugar escondido. El significado que actualmente le damos ha sido extraído de lugares ocultos descubiertos luego que Roma fue incendiada, en donde se hallaron murales decorativos enterrados en lo que hoy conocemos como el Domus Aurea. Próximamente, en el siglo XVI, Rafael Sanzio introdujo esta estética en sus composiciones pictóricas en las Logias que son un tipo de habitación en el Vaticano. A continuación, el manierismo también en el siglo XVI, hace extenso uso de este tipo de vívidas decoraciones en vasijas y otras obras ornamentales. Finalmente y para fijarlo en palabras, el diccionario Merriam-Webster lo define como: "[U]n estilo de arte decorativo caracterizado por formas humanas y animales imaginarias o fantásticas, entretejidas con el follaje o con figuras similares que pueden distorsionar lo natural hasta lo absurdo, lo feo o lo caricaturesco"2. Se viene inmediatamente a la mente el arte de los pintores flamencos Hieronymus Bosch (el Bosco) (1450-1516) y Pieter Brueghel (1525-1569) que anteceden al surrealismo pictórico en cuatrocientos años.

Lo grotesco para Bajtín, tanto en cuanto al análisis del carnaval como manifestación popular como en la versión letrada y escritural de François Rebeláis, representa la voluntaria inversión de los valores éticos y estéticos en el seno de la sociedad medieval. Para el grotesco criollo argentino, por su parte, lo grotesco representa la tensión entre la concepción ideal de la realidad impuesta por el Estado con su ideología nacionalista, a las masas de inmigrantes y campesinos pobres, vis a vis la realidad social que ellos deben enfrentar y sobrellevar cotidianamente (por su falta de habilidades técnicas, nivel de educación, prestigio social, color de piel, idioma, acento, etc.). En ambos casos, tanto en la concepción bajtineana como en la de los autores del grotesco criollo argentino, máscara y grotesco vienen a formar, aunque con diferentes énfasis y connotaciones, una alianza estética que define, genera y opera significados en conjunto; por tanto la máscara implica lo grotesco y lo grotesco implica la máscara para nuestros propósitos.

\footnotetext{
${ }^{2}$ [A] style of decorative art characterized by fanciful or fantastic human and animal forms often interwoven with foliage or similar figures that may distort the natural into absurdity, ugliness, or caricature (Traducción del autor).
} 
Para el tema y el análisis que le concierne a este artículo, los tipos de máscara que estaré más interesado en examinar y contrastar dentro del contexto grotesco son dos: la máscara como herramienta de ecualización social, como en el caso de lo carnavalesco que introduce Bajtín y la máscara como herramienta de conformación social como en el caso del grotesco criollo argentino. Mediante la comparación de estos dos usos emblemáticos de la máscara me parece que se comprenderá mejor el teatro argentino del primer tercio del siglo XX, la urgencia de su denuncia estética y su relación antiestética con la máscara del carnaval premoderno. También creo que podrá visualizarse, aunque sea parcialmente, la diferencia del rol de la literatura en uno y otro momento.

\section{LO CARNAVALESCO}

Para analizar el concepto de máscara en Bajtín es preciso contextualizarla con la práctica del carnaval y lo carnavalesco. En Rebelais y su mundo, Bajtín nos introduce a este concepto como un tema fundamental de la Edad Media en el que la sociedad estratificada en su conjunto participa en esta celebración donde se suspenden todas las normas sociales paralelamente con el ejercicio del sentido común, dando lugar a una situación semiorgiástica en que cada quien no es cada cual, sino más bien el "otro". El débil se transforma en poderoso, el señor en siervo, el hombre en mujer, el campesino en rey, la prostituta en doncella, etcétera. Se produce una subversión grotesca en la estructura social por las horas o días en que acontece el carnaval. Es central recordar que en el carnaval no hay una división entre participantes y observadores que se mantengan distantes y separados entre sí, no es un espectáculo, como los Mardi Grass de la actualidad, sino que la inmersión social en la celebración es completa: la vida subvertida e inmersa en el rito. En el carnaval se suspenden todas las leyes y normas socialmente aceptadas tanto políticas como religiosas: el carnaval es tierra de nadie y tierra de todos simultáneamente, en términos aristotélicos una auténtica catarsis, un modo de mantener saludable el Orden establecido mediante la excepción como control social.

La importancia que Bajtin le asigna a Gargantúa y Pantagruel consiste en que esta obra representa uno de los paradigmas culturales fundamentales en la transición entre el medievo y la modernidad. Gargantúa y Pantagruel es un texto que pone por escrito lo que hasta ahora había sido una expresión física, estética, social y popular del orden católico tradicional (el carnaval). Su itinerario va desde la apertura de las calles para imitar, burlarse, desmitificar y desacralizar el orden feudal establecido y opresivo de la villa medieval, a una nueva dimensión domesticada y contenida por las páginas de un libro. El resultado: la transmutación del carnaval a lo literario tipográfico con sus implicaciones de encierro y ocultamiento, y también como artefacto de control de la subversión social mediante la escritura literaria. El confinamiento del carnaval a las páginas de un libro es parte constituyente de la redefinición cultural occidental con el advenimiento/implementación de la modernidad. 
La máscara de Mijaíl Bajtín es el antifaz que esconde el rostro consuetudinario para definir una nueva posición social representada por el ocultamiento de la cara legitimada por la estructura social de la normalidad, de aquel espacio-tiempo que Bajtín llama cronotopo. La elección del tipo de máscara utilizada en el carnaval medieval es una elección individual (no es impuesta directamente desde arriba), porque está conectada con los roles ordinarios de los diferentes miembros de esa sociedad que son transformados mediante lo carnavalesco en su opuesto iconoclasta y liberador. Con el nacimiento de la modernidad y su insistencia en el concepto de civilización por sobre numerosos otros posibles contenidos culturales, el contenido de lo grotesco en el carnaval si bien no es borrado de la imaginación, es confinado a los estantes de las oscuras y solemnes bibliotecas renacentistas, que al final del día solo puede ser alcanzado por eruditos del siglo de las luces para hablar, especular, teorizar o soñar con él.

\section{A PARTIR DE GOBERNAR ES POBLAR}

Juan Bautista Alberdi en su libro Bases, publicado en Chile en 1852, define desde el exilio el arte de dirigir un país mediante su celebre frase "gobernar es poblar". Cincuenta años más tarde, a comienzos del siglo XX, en Buenos Aires, los transatlánticos provenientes de Europa aún continúan desembarcando emigrantes sobre las costas rioplatenses para repoblar el territorio nacional. Esta idea de Alberdi en pocas décadas se transforma en misión patriótica, especialmente luego de 1884 cuando el ejército argentino termina de erradicar de las pampas a los llamados indios ranqueles (mapuches), pero también debido a las bajas sufridas por gauchos y africanos (Marín Fierro) usados como carne de cañón para luchar contra los mapuches y de este modo aprovechar de blanquear la población del país por ambos lados de la línea de fuego.

El pensamiento de Alberdi no solo imaginó la inmigración en términos cuantitativos (si fuera así para qué haber despoblado el interior de gauchos, indios $y$ negros en primer lugar), sino que principalmente la inmigración fue concebida para consolidar la influencia civilizadora de Europa (Bases). No es de extrañar entonces que los europeos, específicamente del norte del continente (alemanes, holandeses, belgas, ingleses, etc.), fueran considerados las etnias legítimas para tal empresa. El positivismo de la mano con el darwinismo social de Spencer alcanzó en aquellos años especial relevancia dentro de la racionalidad de los constructores nacionales rioplatenses y lo utilizaron como paradigma para construir la moderna Argentina.

Una vez consensuado y en marcha el proyecto de repoblación, de acuerdo con David Rock en Argentina 1516-1987, la inmigración al Río de la Plata va en constante aumento desde un número de inmigrantes neto de 29.441 personas en 1892 a 145.359 inmigrantes para 1913. Los momentos más altos del evento inmigratorio ocurren en 1906 con 198.397 y 1912 con 206.121 personas, respectivamente. Entre 1892 y 1913 el total neto de inmigrantes a la Argentina fue de 2.055.947. La población total encuestada 
en el censo de 1895 fue de 3.954.911 habitantes, la que llegó en 1913 a 7.652.000. Es decir, la inmigración en Argentina en los siguientes 21 años aumentó 52\% respecto de la cifra del censo de 1895. Rock señala: "Para 1914 alrededor de 1/3 de la población nacional había nacido en el extranjero, y alrededor de un $80 \%$ de la población se componía de inmigrantes o descendientes de inmigrantes desde 1850" (166). ${ }^{3}$

Considerando lo anterior, uno de los problemas mayores que se les presenta a los ideólogos y constructores nacionales argentinos de la época es que la inmigración concreta no proviene mayoritariamente del norte de Europa sino del sur y del este del continente, incluso del Medio Oriente, indicando que la constitución racial y étnica de estos futuros argentinos no corresponderá a los ideales de la civilización, progreso y modernidad que sus promotores habían aspirado para ella. Por ejemplo Rock señala que para 1914 vivían en el país 800.00 españoles, 1.000 .000 de italianos, además de 94.000 rusos y polacos, y 80.000 turcos otomanos (que incluyen a libaneses, sirios y judíos). Considerando la sucesión de crisis económicas y políticas de Argentina en ese tiempo, podemos imaginar cómo la ideología de Spencer, hegemónica en selectos sectores de occidente (y luego transformada en Eugenesia), iba "explicando" a la clase gobernante por qué Argentina no corría la misma suerte que EE.UU. Desde nuestra perspectiva, sin embargo, la inmigración al Río de la Plata, por ser una empresa pensada y ejecutada por un país menor y dependiente, dentro del sistema mundial de aquella época, no podía ser capaz de controlar todas las variables significativas de la macroecuación (inmigración, economía, tecnología, mercados internacionales, etc.), especialmente frente a los ingresos disminuidos producto del efecto de la Primera Guerra Mundial. Así describe esta situación David Rock:

Luego del colapso de Baring en 1890, las inversiones conectadas entre Argentina y Gran Bretaña fueron felizmente reavivadas e inmediatamente antes de la primera Guerra. Argentina e Inglaterra estuvieron más cercanas que nunca. Pero luego de la guerra, el vínculo dejó de desarrollarse y mostró signos de obsolescencia. La disminución de la conexión inglesa fueron el presagio de la crisis, para finales de los años veinte, a pesar de su evidente aire de prosperidad, Argentina encaró un futuro incierto. ${ }^{4}$

Este escenario de desajuste estructural político-económico que demandaba e importaba mano de obra barata, especializada y no especializada, para conseguir un crecimiento económico acelerado, fue abortado por los intereses y políticas de las

\footnotetext{
${ }^{3}$ By 1914 around one-third of thee country's population was foreign-born, and around $80 \%$ of the population comprised immigrants and those descended from immigrants since 1850 (Traducción del autor).

${ }^{4}$ After the baring Crash of 1890, the investments links between Argentina and Great Britain were successfully rekindled, and immediately before World War I Argentina and Britain were closer than ever. But after the war the tie failed to further develop and showed signs of obsolescence. The waning of the British link was a harbinger of crisis; by the late 1920s, despite its outward air of prosperity, Argentina faced an uncertain future. (Traducción del autor).
} 
grandes potencias (saturación del mercado internacional, caída de los precios de las materias primas, Primera Guerra Mundial) quedando el país con un enorme desempleo especialmente en Buenos Aires, provocándose la recesión de 1920 y 1921, mientras se seguían importando emigrantes como si no pasara nada ${ }^{5}$. Esta situación que se prolongó por más de quince años contribuyó a la creación de una subcultura marginal, domiciliada principalmente en los arrabales y conventillos de Buenos Aires y que en su mayoría provenía de aquellos países o sectores menos aptos para la civilización ${ }^{6}$.

\section{EL GROTESCO CRIOLLO}

Este contexto de subempleo y marginalidad, en particular para los inmigrantes (y también para los criollos pobres y exgauchos desplazados del campo), es el caldo de cultivo miserable, pero no por eso menos creativo, donde surgen dos grandes artes nacionales: el tango y el teatro grotesco criollo. Ambas manifestaciones artísticas brotan de la frustración y el deseo de expresión y validación de los sectores populares acosados por un sistema socioeconómico y político que literalmente los ha estafado, y ambos con el pasar del tiempo, el teatro y la música/danza llegarán a ser sólidos emblemas del arte argentino del siglo XX.

A pesar que el destino de ambos fue distinto, sobre todo por la mayor flexibilidad de un género respecto del otro, el tango llegó a imponerse como una de las danzas eróticas más seductoras y encantadoras del mundo occidental, mientras que el grotesco criollo comenzó su declinación después de mediados de los años treinta, desde la última obra de Armando Discépolo, "El Relojero" (1934), hasta su virtual desaparición en 1959 con la composición "Narcisa Garay, mujer para llorar" de Juan Carlos Ghiano. Su origen popular, y la honesta representación de las dificultades que este enorme flujo de inmigrantes sobrellevó para poder subsistir, fueron la base de ambas artes rioplatenses. En suma, el tango y el grotesco criollo por su fundación demográfica y experiencia vital de sus autores, comparten sus principales motivos: la tristeza, el abandono, la soledad, la explotación, la delincuencia, el despojo, el alcohol, el adulterio, la nostalgia, la dignidad, entre otros, son temas que estuvieron hasta tal punto conectados en el imaginario de las dos primeras generaciones llegadas a Buenos Aires en el siglo XX, que en los hermanos Discépolo (Enrique Santos y Armando) tenemos un óptimo ejemplo de lo afirmado: al mismo tiempo fueron

\footnotetext{
5 Entre 1921 y 1930 llegaron 1.397 .000 y se regresaron 519.000 , quedando un neto de 878.000 inmigrantes, por ejemplo. El número descendió a 73.000 en la década 1931-1940, y volvió a ascender en los próximos 25 años, entre 1941-1965 a 908.000. Fuente: 4th National Census.

${ }^{6}$ Esta fue una época de gran efervescencia política y social en Argentina, como el levantamiento de los estudiantes en Córdova en 1917, el aumento de las huelgas en las industrias, instigadas por grupos anarquistas y luego socialistas para conseguir mejores condiciones laborales, y el consiguiente efecto en la política partidista argentina en los tiempos del fundador del partido radical (populista) Irigoyen.
} 
lúcidos libretistas del grotesco criollo como inspirados compositores de tango (Cambalache, por ejemplo).

En el grotesco criollo la máscara cumple una función contrapuesta a la descrita por Bajtín en su trabajo acerca del carnaval en los tiempos medievales europeos. En primer lugar la máscara grotesca no es una máscara física de papel, porcelana, totora o madera, sino una máscara simbólica que se expresa mediante diversos códigos socioculturales como la doble valencia del lenguaje, el fracaso del héroe o heroína (por encarnar valores e ideas que no les corresponde como clase o etnia), el deambular entre dos mundos: uno ajeno por la distancia física (Europa, el interior rural), el otro ajeno por la distancia económica y cultural (los medios monetarios, la lengua, las maneras educadas) respecto de los ideales sociales, nacionales o civilizados que se esperaba de ellos. La máscara tiene que ver con una integración forzada (cultural, valórica, psicológica y nacionalista) que les obliga a estar reducidos a una situación de indefensión y frágil pasividad respecto de la macronarrativa dominante. De acuerdo con Kaiser: "[P]ara los personajes grotescos, la máscara no es solo una forma de aparecer frente al mundo sino también, y muy preponderantemente, una manera de verse a sí mismos" (65).

Esta idea es medular para nuestra discusión porque apunta, más allá de los consabidos problemas de subsistencia, muchas veces dramáticos, directamente al asunto de la identidad y como consecuencia a la sanidad mental de la población popular. Si aceptamos que toda cultura debe ser capaz de resolver al menos tres problemas básicos: la subsistencia, la identidad y lo metafísico/ontológico; vemos que la máscara grotesca ${ }^{7}$ viene a constituir y a instituir un mecanismo psicológico autodestructivo tanto individual como socialmente ${ }^{8}$.

Uno de los méritos de este teatro popular es que expone el tipo de autodestrucción impuesta (no solo material, sino que también psicológica) a la que estos nuevos argentinos estaban sometidos y se sometían'. La máscara por lo tanto afecta los tres problemas centrales de la cultura. 1. A la subsistencia, porque al comportarse dentro de la racionalidad de un mundo donde las normas sociales aceptadas no son operativas ni realistas (no debes robar-debes de trabajar-no hay trabajo), el único espacio que les queda a estos inmigrantes y criollos pobres para no dejar de respirar es la mendicidad, la prostitución o para los más afortunados un trabajito en la base de la pirámide social o como mercachifles. 2. De identidad, porque el hecho de hablar otra lengua, basarse en otras (sus propias) costumbres y valores, otras maneras de concebir el mundo, la amistad, el matrimonio, el trabajo, etc., les hacen dudar del valor de sus propias formaciones y sociedades de origen y como

\footnotetext{
${ }^{7}$ Por intentar hacer pasar inadvertidos en la sociedad urbana argentina a los campesinos y a los extranjeros desplazados de su propia tierra.

8 "Matar al indio para salvar al hombre", Richard H. Pratt (es decir, genocidio cultural en vez de racial o biológico).

${ }^{9}$ La versión criolla de lo que se conoce como opresión internalizada.
} 
corolario poner en duda el valor de sí mismos como individuos y como grupo cultural. 3. También lo metafísico es afectado, porque por su mera calidad de humanos, con su propia cosmovisión e ideas de trascendencia (aunque muchos fueron católicos, pero también habían judíos, musulmanes y cristianos ortodoxos) también son puestas en duda porque... ¿No es el fracaso sostenido un castigo de Dios? ${ }^{10}$ Kaiser nos recuerda: "La crisis surge cuando el personaje se ve empujado a pesar de sí mismo a enfrentarse con la verdad, entendido esto último como la realidad desmitificada" (65).

Si la máscara en el mundo de Bajtín tiene como objeto el control social catártico de la opresión aristocrática medieval, por medio de una subversión estratégicamente controlada, la máscara en el grotesco criollo tiene por finalidad representar la asimilación involuntaria y cuasicaricaturesca de los emigrantes al sistema socioeconómico criollo y principalmente político de Argentina. Mientras la máscara carnavalesca se desarrolla en un espacio ritual simbólico, la máscara del grotesco criollo no se manifiesta dentro de un espacio ritual carnavalesco, sino que directamente en el mundo de la cotidianeidad pública, y lo que es mucho más grave, también privada. Para responder a esta disyunción entre ambos modelos, el modelo de Bajtín nos ayuda a explorar la idea de la interacción que ocurre entre estos dos mundos paralelos (el ideal y el real) que cuando se tocan producen un extraordinario arco de energía (el carnaval o el ocultamiento), porque ordinariamente conviven sin reconocerse. En el primer caso la energía es positiva: fluye, arrasa e ilumina como una supernova, en el segundo la energía es negativa: desciende, asfixia y oscurece. La energía del carnaval se disipa y almacena en los recuerdos para alumbrar los malos momentos del resto del año. La energía del grotesco criollo es como un hoyo negro, absorbe sin producir luz ni movimiento: nada hay para recordar, todo es un barroso presente.

Claudia Kaiser nos ayuda a analizar y comprender las distintas formas que la máscara toma para que esta población de trabajadores, privados de sus derechos en un país extranjero (país que tenía el sueño de tener un proceso en castellano similar al de los EE.UU. en inglés) pudiera ser aceptada por el simple motivo de haber sido invitada a participar en su desarrollo. Al no ser este el caso y con el paso del tiempo, una de las formas más penetrantes y autodestructivas de integración social representadas en la Argentina finisecular y hasta la Segunda Guerra Mundial, ha sido representada por el uso de la máscara en el grotesco criollo. La función principal de la máscara en el teatro de la inmigración, es la de esconder el rostro del emigrante y criollo pobre, quienes han sido desplazados a la periferia de Buenos Aires, no para alcanzar la ilusión catártica de probar la igualdad por algunas horas al año, sino para defender contradictoriamente (como lo haría un paciente con un Trastorno Límite de Personalidad) la integridad física y la subsistencia a costa de la integridad emocional y psicológica de quien la lleva. La

\footnotetext{
${ }^{10}$ Como lo señala el cronista Francisco López de Gómara que el cielo se abrió y apareció el santo Santiago Matamoros para ayudar a los cristianos y ganar la batalla en contra de los idólatras aztecas también en el cielo. La derrota es por supuesto un designio de Dios.
} 
máscara grotesca es utilizada como una forma de camuflaje para pasar inadvertido y poder integrarse a la nueva sociedad sudamericana, no para sobrepasarla, reírse de ella o ni siquiera para disfrutarla, sino para morigerar sus efectos discriminatorios. La primera (Bajtín) ha sido concebida para la transgresión y la segunda (grotesco criollo) para la adaptación. Claudia Kaiser señala:

"Si este teatro reconoce en el ser humano una dimensión interior, también reconoce que está preso bajo una máscara; ahogado por la postura que la necesidad de vivir y funcionar dentro de la sociedad le obliga a asumir" (57).

Y como consecuencia de todo esto, Kaiser comenta: "Cuando el hombre no puede objetivar su esencia ética en la acción concreta se convierte en un ser escindido" (71).

\section{LA ESCISIÓN}

El grotesco criollo poetiza y analiza estéticamente esta situación de fragmentación y contradicción psicológica que sufre el emigrante debido al doble estándar que le es impuesto por la sociedad que lo recibe. Por una parte lo convoca y le ofrece un futuro brillante en el sur del mundo, por la otra se encuentra, una vez arribado, que debe moverse a los rincones menos prometedores de la ciudad y la sociedad (algunos al campo, La Gringa, 1904, de Florencio Sánchez), donde es absorbido por el anonimato, la pobreza y el silencio, o simplemente por el efecto de la desconfianza de los lugareños. El asunto, sin embargo, no solo implica un efecto psicológico individual sino un contenido sociológico y de psicología social profunda que afecta a la colectividad inmigrante y desplazada tanto como (aunque de manera asimétrica) a la sociedad argentina en su conjunto.

En psicoanálisis escisión significa un desgarro entre el mundo consciente y el mundo inconsciente de un sujeto, o también puede verse entre la persona (como máscara) y el ser de esa persona que en castellano ha sido traducido como "yo" y en inglés como "self" ". Kaiser explica:

El proceso es el de reducción. Su naturaleza de ser moral se invalida y esta inoperancia implica una deshumanización, en cuanto a que su proyección en el mundo se trunca, se torna caduca. Al no poder autorrealizarse en la sociedad, pierde objetividad. A este proceso de reducción moral se une la caducidad de su proyección laboral-activa en el mundo (71).

Como apuntaba anteriormente la máscara del carnaval es disruptiva y catártica, en cambio la máscara del grotesco criollo es asimilacionista y autoopresiva. Si para los sujetos medievales la máscara constituía su entrada temporal al mundo de la

\footnotetext{
${ }^{11}$ La palabra self se traduce como "yo" en castellano pero "self" significa no la manifestación que acontece por la interacción entre el superyó y el ello, sino que se refiere a lo que constituye la base de nuestra existencia, algo así como el "espíritu que nos anima", o el ojo inicial que mencionaba anteriormente.
} 
igualdad, para los actantes del grotesco criollo la máscara es su entrada a un mundo ancho y ajeno ${ }^{12}$ donde su asimilación forzada a un sistema, para ellos prácticamente disfuncional, es la única opción ofrecida por el anfitrión. Para hacer justicia vale la pena señalar que el anfitrión tampoco era muy libre de implementar una política menos dependiente por ese tiempo, debido a que el proyecto económico y político del Estado argentino utilizaba como modelo paradigmático a las mismas potencias que oscurecían su percepción y restringían su poder de decisión.

$\mathrm{Si}$ las causas ambientales de las enfermedades mentales generadas en niños y niñas son producto del abandono, la indiferencia, las golpizas o incluso el "exceso de cuidado", es decir, por falta de equilibrio emocional en la atención de los pequeños; si como se sabe, el período entre los seis meses y los cinco años de edad es el momento definitorio en la formación psicológica infantil (impronta, detención del desarrollo cognitivo) y que lo que ocurre en este espacio de tiempo va a determinar la forma de ver y sentir el mundo (percepción, cosmovisión emocional) sobre el que cada niña y niño va a apoyar sus percepciones, juicios y valores cuando sea adulto; si trasladamos este efecto de sustrato a millones de emigrantes (niños y adultos) huyendo de la traumatizante Europa en crisis de pre y postguerra, recibidos por una patria/ padre que los desprecia y arrincona; se puede comprender mejor el efecto mental y social producido por la indiferencia deshumanizante recaída sobre estos pueblos. Ese es el material que el grotesco criollo intenta hacer patente y consciente en el público, para beneficio del mundo o de los valores que dice defender la civilización.

La estadística, el número sin rostro, el vale para el hotel de inmigrantes, el tranvía para ir a hacer las filas de los puestos de trabajo cada vez más escasos y miserables, la vida en los conventillos, el mal olor y las enfermedades, la falta de seguro médico, el paso del tiempo donde todo permanece inmóvil, el alcohol barato, la hija embarazada por el compadrito, el hijo atravesado por un cuchillo, la esposa tísica, el abandono consistente y temprano de la escuela, el italiano, el árabe, que no se entienden, la bataclana, la cana, el lunfardo, los emigrantes: vida a la izquierda... estadísticas a la derecha.

Cuando el carnaval de Bajtín se va a la clandestinidad mediante la pluma de Rebeláis, el rito deja de ser un evento sociocultural orgánico y directo para transformarse en una representación literaria mediatizada por el lenguaje escrito, la imprenta y el alfabetismo. El carnaval es domesticado por la modernidad transformándose en un evento carente de vitalidad, encerrado en las hojas de un libro para el placer de los eruditos y la gente letrada. El carnaval se transforma en una curiosidad histórica y estética apto para los estudios de las ciencias sociales y humanas o los trabajos literarios, pero desaparecido del quehacer público concreto.

El gran ganador en este cambio de época es el nuevo género novelístico, el que es capaz de incorporar en sus líneas a la cultura entera mediante sus múltiples voces (poliglosia) y por medio de sus distintos puntos de vista -incluso contradictorios-

\footnotetext{
${ }^{12}$ Parafraseando el título del libro más conocido de Ciro Alegría.
} 
(heteroglosia), en contraposición a la épica clásica con su elemento heroico y su estructura circular. Con el advenimiento de la imprenta se incorporan las lenguas vernáculas locales desplazando rápidamente al latín, llevándola en pocos siglos a su calidad actual de lengua muerta, y elevando las lenguas vernáculas a constituir el material propio de las literaturas nacionales. Es irónico y paradójico desde el punto de vista de la intensión original catártica del carnaval, que esta transformación de la expresión folklórica haya terminado conformando los primeros temas y representaciones de las "literaturas nacionales" europeas, y que estos prototextos (no literarios sino carnavalescos) fueran parte de la genealogía de su literatura clásica: Dante (Divina comedia), Erasmo (Elogio de la Locura), Boccacio (Decamerón), Shakespeare, Cervantes o Rebelais, entre otros.

\section{CONCLUSIONES}

La idea del arte-vida que se desprende de la práctica del carnaval y que luego es reelaborada por la pluma de los escritores transicionales entre la estética medieval carnavalesca y la moderna novelística, ha sido el punto de partida para nuestro examen del concepto de máscara en el grotesco criollo. La principal diferencia entre el uso de una y otra máscara entre el siglo XII y el XV en Europa, respecto de su uso en la Argentina del siglo XIX y XX es muy distinta, contraria, en realidad, pero tienen en común que ambas intentan cubrir el rostro de quien la lleva para conseguir un objetivo ulterior. El objetivo en la máscara carnavalesca es la transgresión de la consuetudinaria normalidad feudal. El objetivo de la máscara en el grotesco criollo es el intento de asimilación a la nueva nación argentina.

La máscara medieval es para degustar, entre risas y placeres inverosímiles por unas horas o incluso por algunos días, lo que constituye la normalidad de la vida de la nobleza y viceversa. La máscara ofrecida por el grotesco criollo es una estrategia textual y metafórica para identificar y denunciar los niveles en que la opresión afectó a los inmigrantes internos (rurales) y externos (extranjeros) cuando se avecindaban principalmente a los arrabales del gran Buenos Aires. Podríamos decir entonces que la máscara carnavalesca es cómica y la máscara del grotesco criollo es trágica.

Aunque el uso de ambas máscaras digitan las cuerdas de lo grotesco, en el carnaval lo grotesco acontece por la yuxtaposición de elementos inadecuados o equivocados de acuerdo con el rango, género, características físicas, etc., de los sujetos participantes. En el grotesco criollo, en cambio, el fenómeno de lo grotesco se manifiesta preferentemente por el fracaso social y personal de quienes deben ocultar su rostro para encajar dentro de un orden doblemente ajeno. Pasivamente ajeno por la distancia física de sus culturas y muchas veces país natal, y dinámicamente ajeno por la simultánea y vertiginosa transformación que ocurre en occidente desde finales del siglo XIX con la segunda revolución industrial (energía, transportes, comunicaciones, ciencia y tecnología) principalmente desarrollada desde los EE.UU., a la que no alcanzan a adaptarse por su condición de marginalidad. 
A pesar que el efecto psicológico producido por el uso de estas dos máscaras es de alienación, la alienación generada por el carnaval es justificada por lo cómico, es transitoria y funciona como una droga para los participantes. Una vez que se pasa el efecto del carnaval hay un retorno a la familiaridad, aunque lacaya, conocida al fin y al cabo. Es cosa de esperar un poco porque con el regreso del ciclo podrá tomarse otra dosis de igualdad. En el caso del grotesco criollo, en cambio, el efecto psicológico es opuesto y devastador, en cada una de las obras, desde Los disfrazados (1916) de Carlos Mauricio Pacheco hasta El relojero (1934) de Armando Discépolo y José de la Rosa, el uso de la máscara implica la utilización de una persona/personaje distante de lo que alguna vez fue y todo aquel cambio es sancionado por la necesidad de sobrevivir en un mundo al que ha sido arrojado por situaciones ajenas a su voluntad. Estos desplazados son producto de un universo que ha sido desbalanceado por las actividades, sueños y proyectos de la nueva elite industrial que va sostenidamente transformándose en monopólica, la que, con y por su nueva perspectiva, está cambiando vertiginosamente las reglas del juego, previniendo que las personas más afectadas por estos cambios tengan la menor posibilidad de opinar o decidir respecto de sus vidas. La salud mental, entonces, se presenta en estas dos tradiciones, la medieval y la moderna, con vectores opuestos, la máscara del carnaval por ser catártica disminuye la tensión existente entre privilegiados y desposeídos, sin pretender eliminar por cierto la opresión, en cambio, la máscara del grotesco criollo acumula -sin resolver- la tensión entre ambos grupos tal como predijo el marxismo con su concepto de lucha de clases. Si el secreto de la práctica medieval es la lubricación de los engranajes del sistema feudal, la máscara del grotesco criollo no tiene más secretos que la conformación del sujeto desplazado a su molde prefabricado de desplazado.

Así como Gargantúa y Pantagruel es la "transcripción" del evento social medieval a las páginas de un libro, para guardar una tradición en vías de desaparición. El grotesco criollo representa lo contrario; es el intento de estos dramaturgos de señalar y develar la humanidad de quienes están detrás de estas máscaras, pero principalmente mostrar el rostro decrépito de la clase gobernante. Ambos fenómenos son mediatizados por la escritura, pero la escritura no solamente utilizada por y con diferentes propósitos, sino que como una consciencia distinta de la naturaleza y el rol de sí misma. De un rol cultural recopilador (para asegurar la memoria de un mundo en vías de desaparición) a uno denunciante (para promover la toma de conciencia e incitar un cambio social). Comienza esta discusión en la época del advenimiento de la escritura vernácula y secular, y concluimos con la crisis del crecimiento, el progreso y la civilización.

En el caso de Rebelais, en Gargantúa y Pantagruel el resultado es una suerte de levantamiento histórico de una realidad en extinción, en este restringido sentido, como la labor de los hermanos Grimm en el siglo XIX en Alemania o como Violeta Parra con la recuperación de las décimas y otras artes campesinas en vías de 
desaparición en el siglo XX en Chile. En el teatro grotesco criollo, en cambio, la utilización de la literatura no es para conservar viejas tradiciones (que por supuesto existen en el corazón de los emigrantes), sino para denunciar prácticas deshumanizadoras. La comicidad del grotesco es trágica y degradante y es lo que, como en el teatro de Bertolt Brecht, produce el distanciamiento entre el público y la secuencia narrativa de la obra. Si pudiéramos compararla horizontalmente (mismo tiempo, mismo lugar) con el referente medieval de Rebelais diríamos que el grotesco criollo habría mostrado la miseria producida por el sistema feudal representado en las villas y por los siervos de la gleba, de un modo más semejante a la empresa emprendida por Cervantes en el Quijote de la Mancha, mediante el dilema presentado entre normalidad y locura.

En ambas mascaradas, sin embargo, vemos interactuar los mismos dos elementos: la sociedad como un sistema simbólico y los sujetos como actantes o signos semióticos dentro de esta metanarrativa. Ambas sociedades aparecen y son opresivas pero la más antigua considera y permite un escape de la cotidianeidad, contiene una válvula que ecualiza las tensiones entre dirigentes y dirigidos, explotadores y explotados. Legitima y alivia la opresión por medio de la risa, la sexualidad, la borrachera, la transgresión. En el caso de países como Argentina que fomentaron y recibieron inmigración de los pueblos mediterráneos, de Europa del este y del medio oriente en el siglo XIX y XX, el asunto es otro; la máscara representa una condena tanto para los inmigrantes domésticos (criollos) como para los mayoritariamente extranjeros. Tanto es así que deben transformarse en el otro para intentar sostener sus necesidades materiales básicas, pero ciertamente condenados, tanto a la alienación de su acervo valórico y cultural originario como a su salud mental.

Por último, la sociedad en su conjunto es afectada en el proceso, porque parte de su base estructural es una herida abierta y supurante. Frente a sus ojos entrecerrados, en la cotidianeidad civilizada, esta sociedad tiene que inventar leyendas y eufemismos para mantener su conciencia respirando delante del desfile de desarrapados y desempleados que pululan por las calles. Entonces es tiempo de culpar a la víctima por su flagrante inadecuación (flojera, suciedad, estupidez), todo esto pasando, mientras la máscara mantiene las cosas en calma esperando que vengan tiempos mejores, que tal vez no vayan a ser otra cosa que el advenimiento de la Segunda Guerra Mundial y el peronismo.

\author{
Ohio University* \\ Modern Languages Department \\ 229 Gordy Hall Athens OH 45701(Estados Unidos) \\ lascar@ohio.edu
}


Heterogeneidad de las máscaras: entre el carnaval de Bajtín y el grotesco criollo de Discépolo

\section{OBRAS CITADAS}

Anderson, Benedict. Imagined Communities. London: Verso, 1991.

Bakhtin, Mikhail. Rebelais and His World. Bloomington: Indiana University Press, 1984.

Derrida, Jacques. Of Grammatology. Baltimore: Johns Hopkins University Press, 1976.

— Margins of Philosophy. Chicago: University of Chicago Press, 1982.

Discépolo, Armando. Obras escogidas. Buenos Aires: Editorial J. Álvarez, 1969.

Freud, Sigmund. Civilization and Its Discontents. Garden City, N.Y.: Doubleday \& Co., 1958.

Galeano, Eduardo. Las Venas abiertas de América Latina. Santiago: Pehuén, 2006.

Gobello, José. Diccionario Lunfardo. Buenos Aires: A. Peña y Lillo, 1975.

Greimas, Algirdas Julien. On meaning: Selected Writings in Semiotic Theory. Minneapolis: University of Minnesota Press, 1987.

Kaiser, Claudia. El grotesco criollo. Cuba: Unidad productora 08 Mario Reguera Gómez, 1977.

Masterton, James. The Narcissistic and Borderline Disorders. New York: Brunner Mazel Publishers, 1981.

Pacheco, Carlos M. Los disfrazados y otros sainetes. Buenos Aires: Universitaria, 1966.

Pampin, Manuel. La Historia del Tango. Buenos Aires: Ediciones Corregidor, 1976.

Quijano, Aníbal. "Colonialidad del poder, eurocentrismo y América Latina". La colonialidad del saber: eurocentrismo y ciencias sociales. Perspectivas Latinoamericanas. Comp. Edgardo Lander. Buenos Aires: CLACSO, 2000: 246.

Rock, David. Argentina 1516-1987. Berkeley \& Los Ángeles: University of California Press, 1987.

Sánchez, Florencio. La gringa y otros textos sobre la inmigración. Rosario: Ameghino Editora, 1999.

Segre, Cesare. Structures and Time. Chicago: Chicago Press, 1979.

Stokstad, Marilyn. Art History. Upper Saddle River, N.J.: Pearson Prentice Hall, 2008.

Todorov Tzvetan. Mikhail Bakhtin. The Dialogical Principle. Minnesota: University of Minnesota Press, 1984.

Viñas, David. Prólogo. Obras escogidas Armando Discépolo. Buenos Aires: Editorial J. Álvarez, 1969. 